\title{
INTRA-OCULAR INVOLVEMENT IN A CASE OF XANTHOMATOUS BILIARY CIRRHOSIS*
}

\author{
BY \\ NANCY LEWIS \\ Melbourne, Australia
}

Xanthomatous biliary cirrhosis is described by Thannhauser (1940) as a form of primary essential xanthomatosis of the hypercholesterolaemic type, the characteristic features of which are the occurrence of biliary cirrhosis; a high total cholesterol content of the blood without a milky serum; and the development of skin xanthomata plana and tuberosa. The skin lesions show a particular distribution in the creases of the palms and soles, on the extensor aspects of the elbows and knees, and over the Achilles tendon. Fluctuating jaundice of long duration is the most outstanding symptom and may lead to a faulty diagnosis of occlusion of the common bile duct by stone or neoplasm. The obstruction, however, is not complete and stercobilin is to be found in the pale faeces. The liver is enlarged and so, usually, is the spleen. The bile acids and bilirubin content of the blood are raised, the alkaline phosphatase is very high, and the serum protein normal. Although the skin of the eyelids is involved by xanthelasma no description of other ocular manifestations can be found in the literature and therefore the following case is reported.

\section{Case Report}

Mrs. B., aged 47 years, began four years ago to suffer some upper abdominal pain, which was followed by the appearance of jaundice and pruritis. Her liver was enlarged and clay-coloured stools were observed. Two years ago xanthelasma appeared on her eyelids and later xanthomata plana in the creases of fingers and toes. Recently she has lost some weight.

Liver biopsy two years ago showed slight increase of small round cells and fibroblasts in the portal tracts.

On present examination, she has rather a dusky greenish-yellow colour of the skin with xanthelasma over both upper and lower eyelids (Fig. 1), with xanthomata plana in the skin creases of the fingers and toes (Fig. 2), and xanthomata tuberosa over both olecranon processes (Fig. 3) and behind the Achilles tendon. She has a punctate ulceration due to scratching of the body.

The liver is enlarged but the spleen is impalpable. The urine is bile-stained and contains pigment with no increase of urobilin. The faeces are clay-coloured, stercobilin is present, and occult blood has not been detected.

The results of liver function tests may be tabulated as follows:

Serum bilirubin increased.

Hippuric acid excretion, $1.3 \mathrm{~g}$. in 4 hours.

Cephalin flocculation test, +++ .

Alkaline phosphatase, 42 units (King Armstrong).

* Received for publication October 24, 1949. 


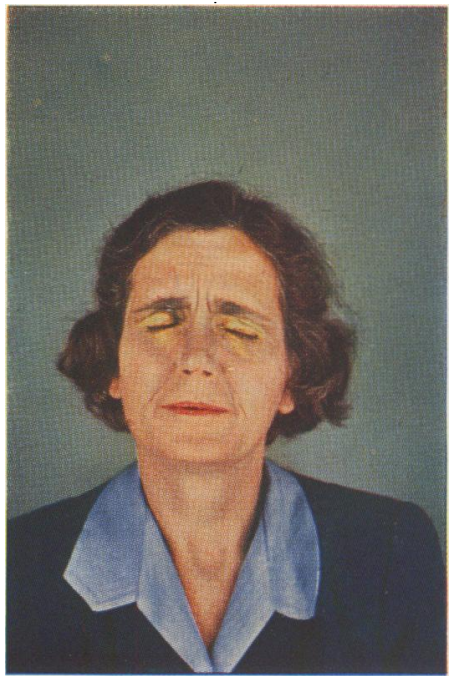

Fig. 1.-Patient showing jaundice and xanthelasma of eyelids.

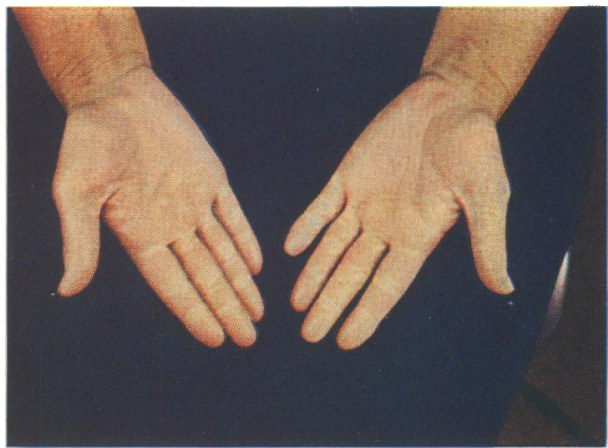

Fig. 2.-Xanthomata plana occurring along the skin creases of the fingers.

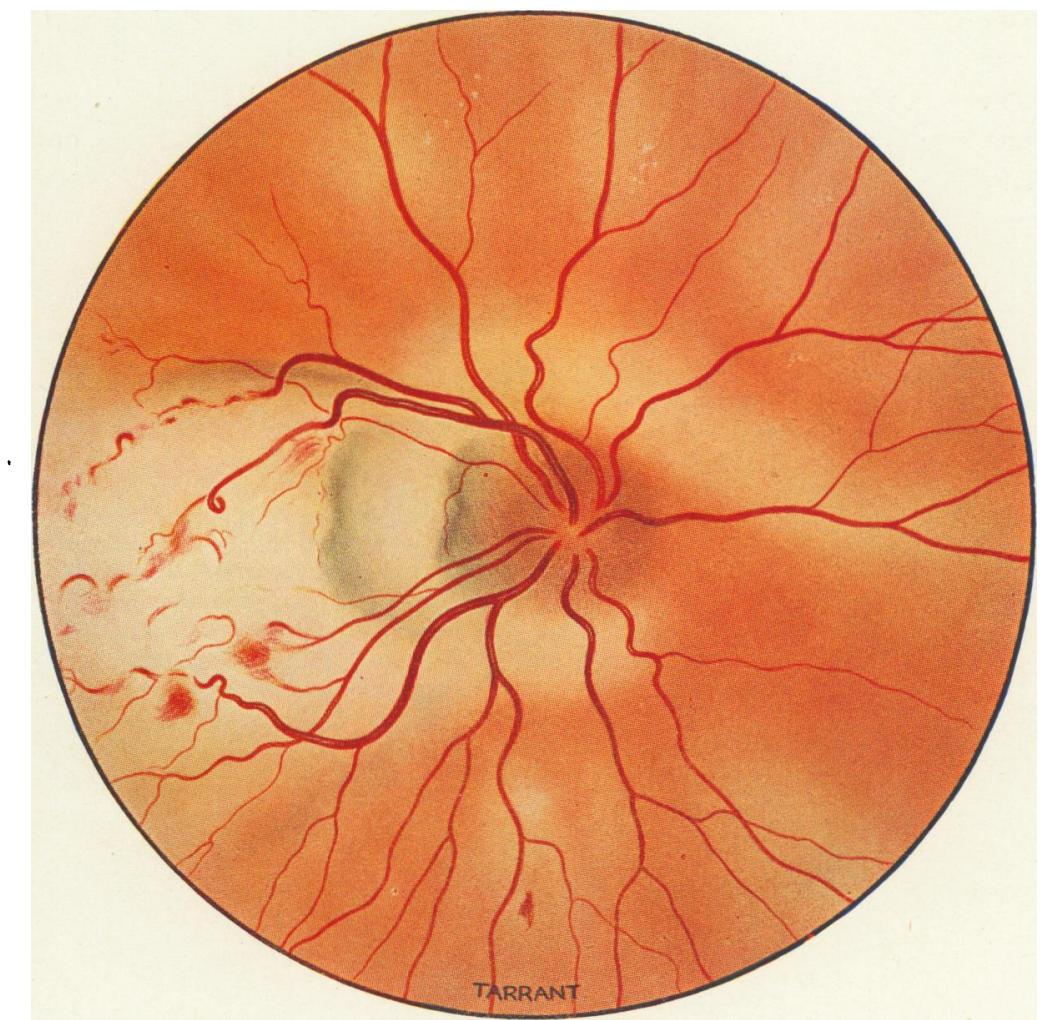

Fig. 4. Appearance of right fundus. 
Total serum protein, 6.5 g. per cent.

albumin, 3.6 g. per cent.

globulin, 2.9 g. per cent.

gamma globulin, $1.34 \mathrm{~g}$. per cent.

Prothrombin index, 91 per cent.

Bile in urine, pigment, ++ ; salts, + .

The results of other investigations are as follows:

Blood normal, $\mathrm{Hb} 98$ per cent.

Blood cholesterol, $530 \mathrm{mg}$. per cent; serum clear, not milky.

Biopsy of a nodule from the elbow showed a collection of cells containing fatty droplets-reported xanthoma.

All other general investigations were negative.

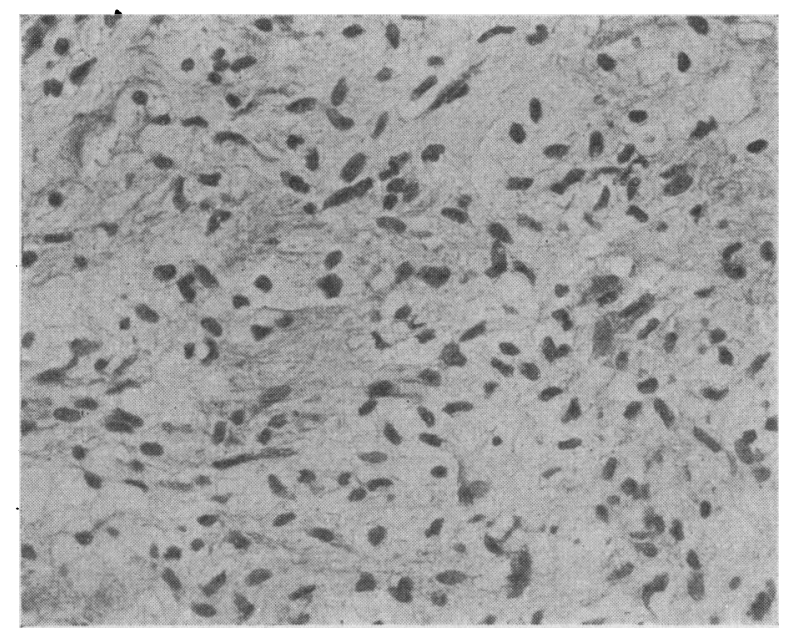

FIG. 3.-Photomicrograph of medium view of a section of xanthomatous tissue removed from the skin over the olecranon process showing typical xanthoma cells.

The patient has submitted to four abdominal operations and laparotomy has failed to reveal any extra-hepatic biliary obstruction. The liver function tests give results suggesting diffuse hepatic damage and there is only a trace of bile entering the bowel. Changes shown at liver biopsy were those of biliary obstruction of biliary cirrhosis rather than those of chronic viral hepatitis or of nutritional liver disease. The raised blood cholesterol and section of the nodule confirm the diagnosis of xanthomatous biliary cirrhosis as described by Thannhauser.

Ocular Symptoms.-These began six months ago with some impairment of vision of the right eye. She noticed what appeared as a floating cloud which persisted for six weeks and then cleared. This was followed by flashes of light three months ago, which were present at all times but were worse in the daylight, and were seen over the whole field of vision. Since then her sight has gradually failed.

Results of examination:

Right eye divergent and conjunctivae icteric.

Vision, right-perception of light only, projection being faulty. left-6/9 with correction.

Right pupil shows sluggish reaction to direct light but reacts normally to the consensual light reflex.

Left fundus appears normal. 
In the right eye can be seen widely scattered yellowish areas involving all parts of the fundus (Fig. 4). These yellowish patches are deep to the retinal vessels, which appear normal except where displaced forwards by the larger collections. The yellowish areas vary in size from fine dots to larger confluent masses. The largest mass forms an extensive tumour involving the lower temporal one-sixth of the fundus, and producing detachment of the retina over it. The retinal vessels in this situation are broken up peripherally, and haemorrhages with oedema of the retina are present. There is also retinal pigmentary disturbance consistent with its displacement by these collections. The disk margins are indistinct owing to the presence of the surrounding swellings.

Although it has not been possible to section the eye, it may be assumed that there are xanthomatous collections in the fundus similar to the xanthomata present elsewhere in the body.

\section{Summary}

A case of xanthomatous biliary cirrhosis is described with involvement of the eye by probable xanthomatous tissue.

I should like to thank Dr. Ian Wood of the Walter and Eliza Hall Institute for permission to report this case, Dr. Doig for supplying the clinical notes, Mr. Inglis, clinical photographer at the Royal Melbourne Hospital, for his assistance with the photography, and the Medical Illustration Department of the Institute of Ophthalmology, London, for the painting of the fundus.

\section{REFERENCE}

Thannhauser, Siegried J. (1940). " "Lipoidoses: Diseases of the cellular lipid metabolism'. P. 88, Oxford Univ. Press. New York. 